\title{
Internal seed dispersal by parrots: an overview of a neglected mutualism
}

Guillermo Blanco, Carolina Bravo, Erica C Pacifico, Daniel Chamorro, Karina Lilian Speziale, Sergio A Lambertucci, Fernando Hiraldo, José L Tella

Despite the fact that parrots (Psitacifformes) are generalist apex frugivores, they have largely been considered plant antagonists and thus neglected as seed dispersers of their food plants. Internal dispersal was investigated by searching for seeds in faeces opportunistically collected at communal roosts, foraging sites and nests of eleven parrot species in different habitats and biomes in the Neotropics. Multiple intact seeds of seven plant species of five families were found in a variable proportion of faeces from four parrot species. The mean number of seeds of each plant species per dropping ranged between one and about sixty, with a maximum of almost five hundred seeds from the cacti Pilosocereus pachycladus in a single dropping of Lear's Macaw (Anodorhynchus leari). All seeds retrieved were small $(<3 \mathrm{~mm})$ and corresponded to herbs and relatively large, multiple-seeded fleshy berries and infrutescences from shrubs, trees and columnar cacti, often also dispersed by stomatochory. An overview of the potential constraints driving seed dispersal suggest that, despite the obvious size difference between seeds dispersed by endozoochory and stomatochory, there is no clear difference in fruit size depending on the dispersal mode. Regardless of the enhanced or limited germination capability after gut transit, a relatively large proportion of cacti seeds frequently found in the faeces of two parrot species were viable according to the tetrazolium test and germination experiments. The conservative results of our exploratory sampling and a literature review clearly indicate that the importance of parrots as endozoochorous dispersers has been largely under-appreciated due to the lack of research systematically searching for seeds in their faeces. We encourage the evaluation of seed dispersal and other mutualistic interactions mediated by parrots before their generalized population declines contribute to the collapse of key ecosystem processes 
1 Internal seed dispersal by parrots: an overview of a neglected mutualism

2

3 Guillermo Blanco $^{1 *}$, Carolina Bravo ${ }^{2}$, Erica C. Pacífico ${ }^{3}$, Daniel Chamorro ${ }^{4}$, Karina Speziale ${ }^{5}$, Sergio

4 Lambertucci ${ }^{5}$, Fernando Hiraldo ${ }^{3}$ and José L. Tella ${ }^{3}$

5

$6{ }^{1}$ Department of Evolutionary Ecology, Museo Nacional de Ciencias Naturales, CSIC. José Gutiérrez

7 Abascal 2, 28006 Madrid, Spain

$8{ }^{2}$ Departament de Biologia Animal, Facultat de Biologia, Avinguda Diagonal 643, 08028 Barcelona, 9 Spain

$10{ }^{3}$ Department of Conservation Biology, Estación Biológica de Doñana, CSIC. Americo Vespucio s/n, E1141092 Sevilla, Spain

$12{ }^{4}$ Departamento de Ciencias Ambientales, Universidad de Castilla-La Mancha, Av. Carlos III s/n, 45071

13 Toledo, Spain

$14{ }^{5}$ Ecotono Laboratory, INIBIOMA (CONICET-National University of Comahue), 8400, Bariloche, 15 Argentina.

$17{ }^{*}$ Corresponding author:

18 Guillermo Blanco, Department of Evolutionary Ecology, Museo Nacional de Ciencias Naturales, CSIC.

19 José Gutiérrez Abascal 2, 28006 Madrid, Spain.

20 Tel: $(+34) 914111328$

21 Fax: (+34) 915645078

22 Email address: gblanco@mncn.csic.es

23

24 Running headline: Endozoochory by parrots 
25

26

27

\section{ABSTRACT}

Despite the fact that parrots (Psitacifformes) are generalist apex frugivores, they have largely been considered plant antagonists and thus neglected as seed dispersers of their food plants. Internal dispersal was investigated by searching for seeds in faeces opportunistically collected at communal roosts, foraging sites and nests of eleven parrot species in different habitats and biomes in the Neotropics. Multiple intact seeds of seven plant species of five families were found in a variable proportion of faeces from four parrot species. The mean number of seeds of each plant species per dropping ranged between one and about sixty, with a maximum of almost five hundred seeds from the cacti Pilosocereus pachycladus in a single dropping of Lear's Macaw (Anodorhynchus leari). All seeds retrieved were small $(<3 \mathrm{~mm})$ and corresponded to herbs and relatively large, multiple-seeded fleshy berries and infrutescences from shrubs, trees and columnar cacti, often also dispersed by stomatochory. An overview of the potential constraints driving seed dispersal suggest that, despite the obvious size difference between seeds dispersed by endozoochory and stomatochory, there is no clear difference in fruit size depending on the dispersal mode. Regardless of the enhanced or limited germination capability after gut transit, a relatively large proportion of cacti seeds frequently found in the faeces of two parrot species were viable according to the tetrazolium test and germination experiments. The conservative results of our exploratory sampling and a literature review clearly indicate that the importance of parrots as endozoochorous dispersers has been largely under-appreciated due to the lack of research systematically searching for seeds in their faeces. We encourage the evaluation of seed dispersal and other mutualistic interactions mediated by parrots before their generalized population declines contribute to the collapse of key ecosystem processes.

Key-words: endozoochorous seed dispersal, fruit size, mutualistic interactions, Psittaciformes, stomatochory, vertebrate frugivores

\section{INTRODUCTION}


51 How organisms mould the environment in which they live by influencing the demography and population

52 dynamics of other organisms is a central issue in ecology (Hooper et al., 2005; Rietkerk \& Van de

53 Koppel, 2008). Factors underlying these processes are being increasingly addressed through the

54 identification of the interacting organisms and the recognition and comprehensive understanding of the

55 nature of their interactions (Wilson, 1992). As a consequence, a detailed natural history and the synthesis

56 of the patterns of interaction among species are continuously merging under the consideration of

57 overlooked ecological linkages and processes of variable complexity, and the probability of being

58 observed in nature (Thompson, 2005; Stang et al., 2007; Loreau, 2010; Bascompte \& Jordano, 2014).

59 Vertebrate frugivores have been repeatedly highlighted as key 'mobile linkers' with a pervasive

60 influence in ecosystem integrity by promoting the interchange of genetic information through seed flow

61 (Fleming \& Kress, 2013; Jordano, 2014). By dispersing their food plants, frugivores can influence the

62 composition and abundance of plant communities, thus playing a major role in ecosystem structure and

63 functioning (Wisz et al., 2013). The importance of frugivores as plant mutualists has traditionally focused

64 on internal dispersal (endozoochory) requiring the ingestion and subsequent defecation or regurgitation of

65 viable seeds to be efficiently dispersed (Fleming \& Kress, 2013; Jordano, 2014). Crucially, the

66 identification of the potential dispersers is essential to fully understand dispersal mutualisms and the

67 influence of each disperser species or group of species on the conservation of ecosystem integrity.

68 Among birds, effective endozoochory has been primarily attributed to fruit gulpers swallowing

69 entire fruits and, to a lesser extent, to fruit mashers feeding on fruit pulp where small seeds can be

70 embedded and then inadvertently swallowed (Fleming \& Kress, 2013; Jordano, 2014). While the size of

71 seeds dispersed by gulpers is constrained by gape-size, it has been argued that dispersal by fruit mashers

72 is restricted only to minute seeds (generally smaller than $2 \mathrm{~mm}$ ), because these frugivores discard larger

73 seeds while biting and mandibulating fruit pulp (Wheelwright, 1985; Fleming \& Kress, 2013; Jordano,

74 2014). Fruit mashers often also act as seed predators, leading to a wide range of interactions across an

75 antagonism-mutualism gradient (Wheelwright \& Orians, 1982; Hulme, 2002). 

actively search for large seeds that are often crushed with the bill to promote digestion, thus acting as seed predators (Janzen, 1981). However, despite the fact that most seed predators have been shown to eventually act as facultative primary dispersers (Norconk, Grafton \& Conklin-Brittain, 1998; Vander Wall, Kuhn \& Beck, 2005), parrots have been largely neglected as endozoochorous dispersers. Although parrots undoubtedly destroy the seeds of many plant species, they can also inadvertently or actively ingest tiny embedded in pulp and disperse them in a viable condition (Fleming et al., 1985; Oliveira, Nunes \& Farias, 2012). Indeed, the Kea, Nestor notabilis has recently been shown to be the major endozoochorous disperser of alpine flora in New Zealand (Young, Kelly \& Nelson, 2012). This suggests that the overlooked potential of parrots in long-distance endozoochory may have precluded the proper evaluation of bird-plant mutualistic networks, and the comprehensive understanding of evolution and coevolution of vertebrate frugivores and their food plants. If endozoochory by parrots is probed, their variable but comparatively large size, high mobility and abundance in frugivorous assemblages (Blanco et al., 2015; Marsden \& Royle, 2015; Renton et al,. 2015, Tella et al. 2015) can be crucial in plant life cycles and ecosystem functioning.

In this study, we evaluated whether a sample of Neotropical parrot species can defecate intact seeds of their food plants. This sampling was conceived as an exploratory study aimed to assess the potential role of parrots as endozoochorous dispersers, rather than to comprehensively evaluate internal dispersal by the sampled species or its consequences for their food plant populations, which requires specific research. Therefore, we did not systematically or seasonally search for faeces, but collected them opportunistically at communal roosts, foraging sites and nests in different habitats and biomes. We also evaluated the viability of the dispersed seeds regardless of their enhanced or limited germination capability due to the transit across the gut. Finally, we conducted an overview of the thus far largely neglected dispersal interactions between parrots and plants, in order to draw attention to their potential implications in plant-frugivore mutualistic networks and forest conservation. 


\section{MATERIAL AND METHODS}

\section{Fieldwork}

104 Fresh faeces were collected at communal roosts, foraging sites and nests of eleven parrot species

105 inhabiting different biomes, including austral and tropical dry, montane and humid forests in variable 106 states of conservation, and urban and agro-pastoral areas, in Ecuador, Peru, Brazil, Chile and Argentina 107 (Table 1).

108 Faeces found beneath the trees used by communally roosting parrots were sampled early in the 109 morning just after parrots left the roosts, which were used by single species thus precluding confusing 110 their faeces with those of other species. Non-adjacent faeces were selected in order to avoid duplication of 111 samples corresponding to the same individual. We also collected several faeces during observations of 112 parrot foraging activity and during the handling of developing nestlings. Access to nests of Lear's Macaw 113 (Anodorhynchus leari) was authorized by the Brazilian government (permit reference SISBIO: 12763-7).

114 Every faecal sample was collected in a paper bag, dried rapidly with a forced-air heater to prevent fungal 115 growth and stored at room temperature until arrival at the laboratory.

116 The main foraging activities and the consumed part of each plant species exploited by parrots

117 were recorded on the same dates and within the surroundings of faecal sampling sites. These observations 118 often corresponded to the flocks attending the communal roosts and breeding areas where faeces were 119 collected. Foraging flocks were recorded during roadside surveys at low speed, making stops to record 120 what they were eating (Blanco et al., 2015). We recorded whether foraging parrots were feeding on pulp 121 of ripe or unripe fruits and their mature or immature seeds, and specifically whether the consumed fruits 122 corresponded to plants with tiny seeds that could be swallowed and pass through the gut into the faeces.

123 The size, measured with callipers, of a sample of ripe fruits of each species consumed by parrots, as well 124 as the number of seeds per fruit, was recorded in the field or extracted from the literature. 
127 Faeces were disaggregated on petri dishes and intact seeds were separated with the aid of binocular

128 microscopes (20x). The seeds were immediately washed with deionized water, gently dried with

129 laboratory blotting paper and stored in paper bags in dark conditions and at room temperature. Seeds were

130 identified and samples of seeds of each species measured for the diameter of the smallest and largest axis

131 to the nearest $0.1 \mathrm{~mm}$ with a digital calliper.

132 The viability of defecated seeds was determined by means of the tetrazolium test (Moore, 1985).

133 This was aimed as an exploratory approach to assess the possibility that defecated seeds retain viability,

134 rather than to precisely determine viability rate. Briefly, the seeds were cut and incubated in a $1 \%$ solution

135 of 2,3,5-triphenyl tetrazolium chloride for 48h; tetrazolium reacts with respiring radicles to produce a red

136 stain indicating viable seeds, while non-stained white radicles indicate non-viable seeds (Moore, 1985).

137 We further assessed the reliability of the tetrazolium test to reflect the potential germination capacity of

138 seeds after parrot gut passage by means of a simple germination experiment; we focused on seeds of the

139 plant more frequently recovered from the faeces. After being washed, 160 seeds of Pilosocereus

140 pachycladus from faecal samples of $A$. leari were set to germinate in petri dishes $(5.5 \mathrm{~cm}$ in diameter)

141 over two sheets of filter paper (Filter-Lab 1300). We used eight petri dishes, with 20 seeds each. Petri

142 dishes were incubated in a chamber at $20^{\circ} \mathrm{C}$ and a photoperiod of $12 \mathrm{~h}$. The petri dishes were regularly

143 watered and sealed with parafilm to prevent them from desiccating. Germination success was scored after

14460 days.

145

146 Overview of seed dispersal by parrots

147 We attempted to find all studies evaluating the presence of intact seeds in parrot faeces in the wild, and

148 those experimentally testing endozoochory in captivity, by using key word searching in ISI Web of

149 Science and Google Scholar. In addition, we surveyed dietary studies and consulted previous literature

150 reviews on diet of parrots (e.g. Matuzak, Bezy \& Brightsmith, 2008; Juniper \& Parr, 2010; Renton et al.,

151 2015) to assess the exploitation of plants with tiny seeds that could be potentially dispersed by

152 endozoochory. 
154 with those potentially dispersed by endozoochory and with those dispersed by stomatochory, using the 155 data reported by Blanco et al. (2015). The size of fruits whose seeds were actually or potentially dispersed 156 by endozoochory was also compared with those dispersed by stomatochory. This overview thus focused 157 on preliminarily exploring the potential role of parrots as seed dispersers of their food plants by different 158 but complementary and redundant mechanisms, and its potential implications in the evolution of fruit 159 traits.

\section{RESULTS}

We searched for seeds in 578 fresh faeces of 11 parrot species on different dates, and in different contexts and habitats in the Neotropics. Overall, we found 1787 seeds of seven plant species of five families in 65 faeces from four parrot species, while the remaining seven parrot species showed no seeds in their faeces

(Table 1). The proportion of faeces with seeds ranged between $\sim 9 \%$ and $\sim 49 \%$ depending on species and context (Table 1). Most faeces with seeds contained seeds from a single species $(92 \%, n=65)$, while the remaining faeces showed seeds of two species of the Cactaceae family (Table 1). The mean number of seeds of each plant species per faecal sample of each parrot species in each context ranged between 1 and 59, with a maximum of 481 seeds of $P$. pachycladus (Cactaceae) in a single faecal sample of $A$. leari (Table 1, Fig. 1).

Parrot species which revealed no seeds in their faeces were mostly foraging on multiple plant

172 parts other than fruit, especially flower buds, nectar, bark and sprouts of native and exotic trees and

173 shrubs, leaves, flowers, bulbs and seeds of grasses, cereal grain from agricultural and grazing areas, and

174 wood parasitic fungi. They were also observed feeding on pulp of large-seeded fruits, both of native and 175 exotic trees and shrubs, and predating on their seeds (Table 1). The results showing few or no seeds in

176 faeces are clearly conservative when the sampling was conducted in seasonal periods with very low

177 abundance of fruit/seeds or lacking fruiting plants (e.g. both Enicognathus species and Cyanoliseus 178 patagonus sampled in late austral winter). 

plant species; seeds of the same plant species found in faeces of different parrot species were pooled.

181 These seeds usually correspond to relatively large, multiple-seeded fleshy berries and aggregates of 182 drupes with juicy pulp from plants of variable growth forms (Table 2). Several of the plant species 183 dispersed by endozoochory were also observed being dispersed by stomatochory (e.g. entire fruits of 184 Rubus sp. dispersed by Psittacara hockingi, and fruits of $P$. pachycladus transported with the feet in flight 185 by $A$. leari).

Results of the tetrazolium test indicated that a proportion of seeds of $P$. pachycladus and Cereus jamacaru retrieved from faeces of two different parrot species and sampling contexts were viable (Table 2). The germination success of a sample of $P$. pachycladus seeds $(35.6 \%, n=160)$ was slightly less but not statistically different (Fisher's exact test $P=0.199$ ) than the proportion of viable seeds as assessed by the tetrazolium test (Table 2), which indicates that this test reliably reflected the potential of seeds to germinate after passing through the parrots' gut. The seeds of the remaining species, which were found much less frequently in faeces, were inviable according to the tetrazolium test (Table 2). stomatochory $\left(\log _{10}\right.$ seed length, two-way ANOVA, $F_{2,26}=23.88, P<0.0001, \log _{10}$ seed width, $F_{2,26}=$ 20.68, $P<0.0001$; post-hoc tests indicated no size difference between seeds actually and potentially dispersed by endozoochory, both $P>0.05$, Fig. 2). The size of fruits whose seeds were actually or potentially dispersed by endozoochory was similar for fruit length $\left(\log _{10}\right.$ transformed, $t$-test, $t=0.304, \mathrm{P}=$ $0.76)$ and slightly larger for fruit width ( $\log _{10}$ transformed, $t$-test, $t=2.07, P=0.049, n_{1}=13, n_{2}=15$ ) than those dispersed by stomatochory (Fig. 3).

\section{DISCUSSION}

202 Despite the fact that parrots have traditionally been neglected as internal seed dispersers, we found seeds 203 of several plant species in a small sample of parrot faeces collected in a variety of habitats and biomes in 204 the Neotropics. The sampled parrot species and populations were not selected for their known frugivorous 
205 habits or local and seasonal use of fruits from particular plant species. Instead, faecal collection

206 opportunities during the course of other studies were occasionally encountered and used to assess

207 endozoochory, even when there were no fruiting plants on the sampling dates. As a consequence, we did

208 not find seeds in the faeces of several of the sampled parrot species because they were not foraging on

209 fruits during the study period, but rather on a variety of other resources. However, as trophic generalists

210 exploiting all seasonally available feeding opportunities (e.g. Ragusa-Netto \& Fecchio, 2006; Gilardi \&

211 Toft, 2012; Lee et al., 2014; Blanco et al., 2015; Renton et al., 2015), these and many other parrot species

212 have been occasionally or frequently recorded exploiting all major neotropical plant families with tiny-

213 seeded fruits (see diet reviews by Matuzak, Bezy \& Brightsmith, 2008; Juniper \& Parr, 2010; Renton et

$214 a l, 2015)$. Therefore, the conservative results of our exploratory sampling and the literature review

215 indicate that the importance of parrots as endozoochorous dispersers has been largely under-appreciated

216 due to the lack of research systematically searching for seeds in their faeces.

As expected from our random sampling contexts, dates and habitats, the proportion of faeces with

218

219

220

221

222

223

224

225

226

227 seeds greatly differed between plant and parrot species. Both the occurrence and number of seeds in faeces were especially high for cacti from the Caatinga, dispersed by a medium-size parakeet ( $T$.

acuticaudata) and a large macaw (A. leari); two other parrot species were recorded foraging on the same cacti species but seeds were not retrieved from their faeces, probably due to the small number of faeces analysed. The recorded figures were similar and even higher regarding the number of seeds per dropping than those reported in the literature for recognized avian frugivores (Fleming \& Kress, 2013; Jordano, 2014), as also reported for the New Zealand kea (Young, Kelly \& Nelson, 2012). Besides Cactaceae, we found seeds from Moraceae, Rosaceae, Asteraceae and Plantaginaceae families. Our review of the literature showed that intact seeds of other plant families have been retrieved from parrot faeces, including Mutingiaceae, Dilleniaceae, Myrtaceae, Araliaceae, Coriariaceae, Elaeocarpaceae, Ericaceae, Podocarpaceae, Polygonaceae, Rubiaceae and Lauraceae (Fleming et al,. 1985; Oliveira, Nunes \& Farias, 2012; Young, Kelly \& Nelson, 2012; Thabethe et al., 2015). Internal dispersal of tiny seeds of these and other plant families were suspected in other studies not searching for seeds in faeces (e.g. Eitniear,

Peer] reviewing PDF | (2015:12:8029:1:1:NEW 17 Jan 2016) 
231 Mcghee \& Waddell, 1994; Norconk, Grafton \& Conklin-Brittain, 1998; Contreras-González et al., 2009;

232 Blanco et al., 2015). The variety of habits, growth forms and seed and fruit types of plants dispersed by

233 endozoochory strengthens the key mutualist role of parrots on plant assemblages by complementing

234 previously recorded interactions, including pollination, stomatochorous seed dispersal, seed facilitation

235 for secondary dispersers and plant healing (Douglas, Winkel \& Sherry, 2013; Blanco et al., 2015; Tella et 236 al., 2015).

237 All seeds found in the faeces were small $(<3 \mathrm{~mm})$ and corresponded to herbs and relatively large,

238 multiple-seeded fleshy berries and infrutescences with juicy pulp from columnar cacti, shrubs and trees

239 (see also Fleming et al., 1985; Oliveira, Nunes \& Farias, 2012, Young, Kelly \& Nelson, 2012).

240 Importantly, parrots are singular dispersers owing to their unique ability to simultaneously or alternatively

241 move minute seeds from fleshy fruits by endozoochory, stomatochory and probably epizoochory (see Fig.

242 1c). Parrots are apparently not limited by gape size to disperse tiny seeds, although the smallest species

243 could crush the smallest seeds, but this requires further testing. Conversely, the smallest species can be

244 limited by body-size to disperse large seeds by stomatochory, but they can still disperse by this method

245 seeds much larger than those dispersed by endozoochory (Boehning-Gaese, Gaese \& Rabemanantsoa,

246 1999; Sazima, 2008; Blanco et al., 2015; Tella et al., 2015). Our exploratory analysis of these constraints

247 suggests that, despite the obvious size difference between seeds dispersed by endozoochory and

248 stomatochory, no clear differences arise for fruit size depending on the dispersal mode. This appears to be

249 primarily due to the widespread range of size and shape of fruits dispersed by stomatochory, including

250 those much longer than they are wide, e.g. multi-seeded pods corresponding to legumes (Fabaceae) and

251 other large fruits (Blanco et al., 2015; Tella et al., 2015). Seed dispersal mutualisms mediated by parrots

252 can thus have multiple potential implications for the understanding of bird-fruit interactions, especially

253 because only internal seed dispersal constrained by gape size has been generally considered as an

254 evolutionary force selecting for avian-dispersed seed size (Wheelwright, 1985; Fleming \& Kress, 2013;

255 Galetti et al,. 2013; Jordano, 2014). 
A large proportion of the cacti seeds frequently found in the faeces of two parrot species were

257 viable according to the tetrazolium test. The maximum germination success in laboratory conditions of

258 seeds extracted from mature fruits of C. jamacaru (94.0\%: Meiado et al., 2010, 89.0\%: Abud et al., 2013,

259 both at $25{ }^{\circ} \mathrm{C}$ and $12 \mathrm{~h}$ photoperiod) was similar to the proportion of viable seeds of the same cacti

260 retrieved from $A$. leari faeces (92.7\%). Germination success recorded by Abud et al. (2010) for $P$.

261 pachycladus seeds in the same conditions was, however, higher than the proportion of viable seeds and

262 germination success of seeds from parrot faeces recorded in this study. Sample size of those species for

263 which seeds were inviable ( $\leq 20$ seeds in all cases) was insufficient to adequately determine this trait,

264 given the variable natural viability of seeds (Long et al., 2015) and the low germinability of several of the

265 recorded species (e.g <35\% in Tacinga inamoema, Nascimento et al., 2015). Seed viability, especially of

266 those seeds from the plant species less frequently found in faeces, could also be affected by the seed

267 drying conditions carried out in the field, and the subsequent storage after analysis, or they may actually

268 be affected by passage through the parrots' gut. Alternatively, these seeds could correspond to immature

269 fruits often exploited by parrots (Norconk, Grafton \& Conklin-Brittain, 1998; Blanco et al., 2015). In any

270 case, our exploratory experiments and findings add to those of previous studies suggesting that parrots

271 can be endozoochorous dispersers enhancing or limiting seed germinability to variable extents depending

272 on plant and parrot species (Fleming et al., 1985; Oliveira, Nunes \& Farias, 2012, Thabethe et al. 2015),

273 as stated for recognized avian seed dispersers (Traveset et al., 2007).

274 In conclusion, despite the fact that parrots constitute an evolutionarily ancient, highly diversified

275 and widely distributed group of generalist apex frugivores (Toft \& Wright, 2015), they have been largely

276 overlooked as seed dispersers of their food plants, and thus excluded from animal-plant interaction

277 networks (Fleming \& Kress, 2013; Bascompte \& Jordano, 2014). This exclusion has likely been

278 promoted by the relatively large size, canopy use and high mobility of parrots, hindering detailed

279 observations of stomatochory (Blanco et al,. 2015; Tella et al., 2015) and, especially due to the difficulty

280 of mist-netting them to collect faeces to evaluate endozoochory. Importantly, this knowledge gap implies

281 a markedly biased view of frugivore-plant mutualistic interactions towards fruit gulpers, despite the fact 
282 that parrots constitute rich species guilds showing a greater range of size, morphology and foraging

283 behaviours, and accounting for a higher density and biomass than other recognized frugivores in many

284 tropical and temperate ecosystems (Blanco et al., 2015; Marsden \& Royle, 2015; Renton et al., 2015; Toft

$285 \&$ Wright, 2015). This supports the emerging view that many species traditionally regarded only as seed

286 predators can also act as pervasive seed dispersers owing to their comparatively high abundance (Heleno

287 et al., 2011; Orłowski et al., 2015). Worryingly, in addition to the loss of frugivore-plant interactions (so

288 far mostly focused on fruit gulpers) due to forest destruction and fragmentation (Markl et al., 2012;

289 Sebastián-González et al., 2015), the intensive persecution and capture of parrots for the pet trade may be

290 decimating populations of once common species (Tella \& Hiraldo, 2014; Annorbah, Collar \& Marsden,

291 2015; Toft \& Wright, 2015), thus disrupting largely unknown mutualistic interactions between parrots

292 and their food plants. We encourage an comprehensive evaluation of seed dispersal and other mutualistic

293 interactions mediated by parrots before their generalized population declines contribute to the collapse of

294 key ecosystem processes.

295

296 ACKNOWLEDGEMENTS

297 We thank G. Manzini, P. Plaza and O. Mastrantuoni, T. Filadelfo, D. Alves, M. Cardoso, J. Carlos

298 Nogueira, M.F. Lacerda da Silva, F. Riera, T.Valença and Fundação Biodiversitas (Canudos Biological

299 Station) for field-work assistance. J. Marcos Rosa kindly cedes his Lear's Macaw photos. We

300 acknowledge the efforts of S. Tollington and two anonymous reviewers in improving the paper's content.

301

\section{REFERENCES}

303 Abud, H.F., Gonçalves, N.R., Reis, R.D.G.E., Pereira, D.S. \& Bezerra, A.M.E. (2010) Germinação e

304 expressão morfológica de frutos, sementes e plântulas de Pilosocereus pachycladus Ritter.

305 Revista Ciência Agronômica, 41, 468-474. 
306

307

308

309

Abud, H.F., Pereira, M.D.S., Gonçalves, N. R., Pereira, D.D.S. \& Bezerra, A.M.E. (2013) Germination and morphology of fruits, seeds and plants of Cereus jamacaru DC. Journal of Seed Science, 35, 310-315.

Annorbah, N.N., Collar, N.J. \& Marsden, S.J. (2015) Trade and habitat change virtually eliminate the Grey Parrot Psittacus erithacus from Ghana. Ibis. DOI: 10.1111/ibi.12332.

Bascompte, J. \&, Jordano, P. (2014) Mutualistic networks. Princeton University Press, Princeton.

Blanco, G., Hiraldo, F., Rojas, A., Dénes, F.V.\& Tella, J.L. (2015) Parrots as key multilinkers in ecosystem structure and functioning. Ecology and Evolution, 18, 4141-4160.

Boehning-Gaese, K., Gaese, B.H. \& Rabemanantsoa, S.B. (1999) Importance of primary and secondary seed dispersal in the Malagasy tree Commiphora guillaumini. Ecology, 80, 821-832.

Contreras-González, A.M., Rivera-Ortíz, F.A., Soberanes-González, C., Valiente-Banuet, A. \& Arizmendi, M.C. (2009) Feeding ecology of Military Macaws (Ara militaris) in a semi-arid region of central Mexico. The Wilson Journal of Ornithology, 121, 384-391.

Douglas, L.R., Winkel, G. \& Sherry, T.W. (2013) Does the bananaquit benefit commensally from parrot frugivory? an assessment using habitat quality. Biotropica, 45, 457-464.

Eitniear, J.C., Mcghee, S. \& Waddell, W. (1994) Observations on the feeding upon Psittacanthus calyculatus by Brown-hooded Parrots (Pionopsitta haematotis). Ornitolologia Neotropical, 5 , $119-120$.

Fleming, T.H., Williams, C.F., Bonaccorso, F.J. \& Herbst, L.H. (1985) Phenology, seed dispersal, and colonization in Muntingia calabura, a neotropical pioneer tree. American Journal of Botany, $\mathbf{7 2}$, 383-391.

Fleming, T.H. \& Kress, W.J. (2013) The Ornaments of Life. University of Chicago Press, Chicago.

Galetti, M., Guevara, R., Côrtes, M.C., Fadini, R., Von Matter, S., Leite, A.B., Labecca F., Ribeiro T., Carvalho C., Collevatti R.G., Pires M.M., Guimarães Jr. P.R., Brancalion P.H., Ribeiro M.C. \& Jordano, P. (2013) Functional extinction of birds drives rapid evolutionary changes in seed size. Science, 340, 1086-1090. 
332 Gilardi, J.D., \& Toft, C.A. (2012) Parrots eat nutritious foods despite toxins. PloS one, 7(6), e38293.

333 Heleno, R.H., Ross, G., Everard, A.M.Y., Memmott, J. \& Ramos, J.A. (2011) The role of avian 'seed 334 predators' as seed dispersers. Ibis, 153, 199-203.

Hooper, D.U., Chapin III, F.S., Ewel, J.J., Hector, A., Inchausti, P., Lavorel, S., Lawton, J.H., Lodge, D.M., Loreau, M., Naeem, S., Schmid, B., Setala, H., Symstad, A.J., Vandermeer, J. \&Wardle, D.A. (2005) Effects of biodiversity on ecosystem functioning: a consensus of current knowledge. Ecological Monographs, 75, 3-35.

Hulme, P. (2002) Seed eaters: seed dispersal, destruction, and demography. Seed Dispersal and Frugivory: Ecology, Evolution and Conservation (eds D. Levey, W. Silva \& M. Galetti), pp. 257273. CABI Publishing, Wallingford.

Janzen, D.H. (1981) Ficus ovalis seed predation by an orange-chinned parakeet (Brotogeris jugularis) in Costa Rica. Auk, 98, 841-844.

Jordano, P. (2014) Fruits and frugivory. Seeds: the ecology of regeneration of plant communities. 3rd edition (ed R.S. Gallagher), pp. 18-61. CABI Publishing, Wallingford.

Juniper, T. \& Parr, M. (2010) Parrots. A Guide to the Parrots of the World. Christopher Helm, London.

Lee, A.T., Brightsmith, D.J., Vargas, M.P., Leon, K.Q., Mejia, A.J., \& Marsden, S.J. (2014) Diet and geophagy across a western amazonian parrot assemblage. Biotropica, 46, 322-330.

Long, R.L., Gorecki, M.J., Renton, M., Scott, J.K., Colville, L., Goggin, D.E., Commander, L.E., Westcott, D.A., Cherry, H. \& Finch-Savage, W.E. (2015) The ecophysiology of seed persistence: a mechanistic view of the journey to germination or demise. Biological Reviews, 90, 31-59.

Loreau, M. (2010) Linking biodiversity and ecosystems: towards a unifying ecological theory. Philosophical Transactions of the Royal Society B, 365, 49-60.

Mark1, J.S., Schleuning, M., Forget, P.M., Jordano, P., Lambert, J.E., Traveset, A., Wright, J. \& Böhning-Gaese, K. (2012) Meta-analysis of the effects of human disturbance on seed dispersal by animals. Conservation Biology, 26, 1072-1081. 
357 Marsden, S.J. \& Royle, K. (2015) Abundance and abundance change in the world's parrots. Ibis, 157,

358

359

360

361

362

363

364

365

366

367

368

369

370

371

372

373

374

375

376

377

378

379

380

219-229.

Matuzak, G.D., Bezy, M.B. \& Brightsmith, D.J. (2008) Foraging ecology of parrots in a modified landscape: seasonal trends and introduced species. The Wilson Journal of Ornithology, 120, 353365.

Meiado, M.V., Correa de Albuquerque, L.S., Rocha, E.A., Rojas-Aréchiga, M. \& Leal, I.R. (2010) Seed germination responses of Cereus jamacaru DC ssp. jamacaru (Cactaceae) to environmental factors. Plant Species Biology, 25, 120-128.

Menezes, M.O.T.D., Taylor, N. P. \& Loiola, M.I.B. (2013) Flora of Ceará, Brazil: Cactaceae. Rodriguésia, 64,757-774.

Moore, R.P. (1985) Handbook on Tetrazolium Testing. The International Seed Testing Association, Zurich.

Nascimento, J.P., Meiado, M.V., Nicola, P.A. \& Pereira, L.C. (2015) Germinação de sementes de Tacinga inamoena (K. Schum.) np Taylor \& Stuppy (Cactaceae) após endozoocoria por Chelonoidis carbonaria (Spix, 1824)(Reptilia: Testudinidae). Gaia Scientia, 9, 9-14.

Norconk, M.A., Grafton, B.W. \& Conklin-Brittain, N.L. (1998) Seed dispersal by neotropical seed predators. American Journal of Primatology, 45, 103-126.

Oliveira, A.K.M., Nunes, A.C. \& Farias, G.C. (2012) Predation of Curatella americana seeds by Aratinga aurea parrots. Revista Brasileira de Biociências, 10, 526-529.

Orłowski, G., Czarnecka, J., Goławski, A., Karg, J. \& Panek, M. (2015) The effectiveness of endozoochory in three avian seed predators. Journal of Ornithology, doi:10.1007/s10336-015$1248-8$

Ragusa-Netto, J. \& Fecchio, A. (2006) Plant food resources and the diet of a parrot community in a gallery forest of the southern Pantanal (Brazil). Brazilian Journal of Biology, 66, 1021-1032. 
381 Renton, K., Salinas-Melgoza, A., De Labra-Hernández, M. Á. \& de la Parra-Martínez, S. M. (2015)

382

383

384

386

387

388

389

390

391

392

393

394

395

396

397

398

399

400

401

402

403

404

Resource requirements of parrots: nest site selectivity and dietary plasticity of Psittaciformes. Journal of Ornithology, doi:10.1007/s10336-015-1255-9.

Rietkerk, M. \& Van de Koppel, J. (2008). Regular pattern formation in real ecosystems. Trends in Ecology \& Evolution, 23, 169-175.

Sazima, I. (2008) The parakeet Brotogeris tirica feeds on and disperses the fruits of the palm Syagrus romanzoffiana in Southeastern Brazil. Bioneotropica, 8, 231-234.

Sebastián-González, E., Dalsgaard, B., Sandel, B. \& Guimarães, P.R. (2015) Macroecological trends in nestedness and modularity of seed-dispersal networks: human impact matters. Global Ecology and Biogeography, 24, 293-303.

Souza, A.C.M.D., Gamarra-Rojas, G., Andrade, S.A.C. \& Guerra, N.B. (2007) Características físicas, químicas e organolépticas de quipá (Tacinga inamoena, Cactaceae). Revista Brasileira de Fruticultura, 29, 292-295.

Tella, J.L. \& Hiraldo, F. (2014) Illegal and legal parrot trade shows a long-term, cross-cultural preference for the most attractive species increasing their risk of extinction. PloS one, 9, e107546.

Tella, J.L., Baños-Villalba, A., Hernández-Brito, D., Rojas, A., Pacífico, E., Díaz-Luque, J.A., Carrete, M., Blanco, G. \& Hiraldo, F. (2015) Parrots as overlooked seed dispersers. Frontiers in Ecology and Environment, 13, 338-339.

Thabethe, V., Wilson, A.L., Hart, L.A. \& Downs, C.T. (2015) Ingestion by an invasive parakeet species reduces germination success of invasive alien plants relative to ingestion by indigenous turaco species in South Africa. Biological Invasions, 17, 3029-3039.

Thompson, J.N. (2005) The geographic mosaic of coevolution. University of Chicago Press, Chicago.

Toft, C.A. \& Wright, T.F. (2015) Parrots of the wild: a natural history of the world's most captivating birds. University of California Press, Los Angeles. 
405 Traveset, A., Robertson, A.W. \& Rodríguez-Pérez, J. (2007) A review on the role of endozoochory on

406

407

408

409

410

411

412

413

414

415

416

417

418

419

420

421 seed germination. Seed dispersal: theory and its application in a changing world (eds A.J. Dennis, R.J.Green, E.W. Schupp \& D.A.Westcott), pp.78-103. CABI Publishing, Wallingford.

Vander Wall, S.B., Kuhn, K.M. \& Beck, M.J. (2005) Seed removal, seed predation, and secondary dispersal. Ecology, 86, 801-806.

Wheelwright, N.T. \& Orians, G.H. (1982) Seed dispersal by animals - contrasts with pollen dispersal, problems of terminology, and constraints on coevolution. American Naturalist, 119, 402-413

Wheelwright, N.T. (1985) Fruit size gape width and the diets of fruit eating birds. Ecology, 66, 808-818.

Wilson, E.O. (1992) The Diversity of Life. Harvard University Press, Cambridge.

Wisz, M.S., Pottier, J., Kissling, W.D., Pellisier, L., Lenoir, J., Damgaard, C.F., Dormann, C.F., Öckinger, E., Schmidt, N.M., Termansen, M., Timmermann, A.,Wardle, D.A., Aastrup, P., \& Svenning, J.C. (2013) The role of biotic interactions in shaping distributions and realised assemblages of species: implications for species distribution modelling. Biological Reviews, $\mathbf{8 8 ,}$ 15-30.

Young, L.M., Kelly, D. \& Nelson, X.J. (2012) Alpine flora may depend on declining frugivorous parrot for seed dispersal. Biological Conservation, 147, 133-142. 
422 Table 1. Results of the searching for seeds in parrot faeces collected in several contexts and Neotropical habitats and biomes. For each parrot species and context,

423 the overall proportion of faeces with seeds was shown. The proportion of faeces with seed of each plant species and the number \pm SD and range of seeds per

424 dropping were also shown. Collection data and feeding observations of parrot species for which no seed was found in the sampled faeces are also shown.

\begin{tabular}{|c|c|c|c|c|c|}
\hline arrot species $\left(\right.$ context $\left.^{\mathrm{a}}\right)$ & Habitat, locality, date & $\begin{array}{c}\% \text { faeces } \\
\text { with seeds, } n\end{array}$ & Plant species (Family) & $\begin{array}{l}\text { Faeces with } \\
\text { seeds }(\%)^{\mathrm{b}}\end{array}$ & $\begin{array}{c}\text { Mean } \pm \text { SD seeds/ faeces } \\
\text { (range) }\end{array}$ \\
\hline \multicolumn{6}{|l|}{ Vith seeds in sampled faeces } \\
\hline \multirow[t]{2}{*}{ sittacara hockingi (CR) } & Montane forest, Leymebamba, Perú, Dec. 2014 & $24.1, n=29$ & Rubus sp. (Rosaceae) & $6(20.7)$ & $3.3 \pm 4.1(1-11)$ \\
\hline & & & Maclura tinctoria (Moraceae) & $1(3.4)$ & 1 \\
\hline \multirow[t]{2}{*}{ Thectocercus acuticaudatus (CR, FA) } & Caatinga, Canudos, Brazil, Jan.-April 2015 & $30.2, n=43$ & Pilosocereus pachycladus (Cactaceae) & $13(30.2)$ & $25.3 \pm 37.8(1-107)$ \\
\hline & & & Tacinga inamoema (Cactaceae) & $1(2.3)$ & 2 \\
\hline \multirow[t]{2}{*}{ Anodorhynchus leari (CR, FA) } & Caatinga, Canudos, Brazil, Jan.-April 2015 & $49.3, n=75$ & Pilosocereus pachycladus (Cactaceae) & $37(49.3)$ & $40.9 \pm 90.8(1-481)$ \\
\hline & & & Tacinga inamoema (Cactaceae) & $3(4.0)$ & $1.0 \pm 0.0(1)$ \\
\hline \multirow[t]{2}{*}{ Anodorhynchus leari $(\mathrm{N})$} & Caatinga, Canudos, Brazil, April 2015 & $22.2, n=18$ & Pilosocereus pachycladus (Cactaceae) & $2(11.1)$ & $8.5 \pm 6.4(4-13)$ \\
\hline & & & Cereus jamacaru (Cactaceae) & $3(16.7)$ & $58.7 \pm 80.8(1-151)$ \\
\hline \multirow[t]{2}{*}{ Myiopsitta monachus (BC) } & Urban, Buenos Aires, Argentina, May 2015 & $8.6, n=35$ & Unindentified Asteraceae & $2(5.7)$ & $2.0 \pm 0.0$ \\
\hline & & & Plantago major (Plantaginaceae) & $1(2.9)$ & 4 \\
\hline \multicolumn{6}{|l|}{ Nithout seeds in sampled faeces } \\
\hline & & $n$ & \multicolumn{3}{|c|}{ Main food exploited during foraging observations } \\
\hline orpus coelestis (CR) & Coastal-urban, Santa Elena, Ecuador, Dec. 2014 & 250 & \multicolumn{3}{|c|}{ fruit pulp (Ficus sp.), nectar, bark } \\
\hline Eupsittula cactorum $(\mathrm{N})$ & Caatinga, Canudos, Brazil, Jan. Feb. 2015 & 10 & \multicolumn{3}{|l|}{ fruit pulp (Cactaceae), flowers, nectar, bark } \\
\hline Imazona lilacina $(\mathrm{CR})$ & Tumbesian forest, Santa Elena, Ecuador, Dec.2014 & 32 & \multicolumn{3}{|c|}{ fruit pulp (mostly Spondias purpurea, Cordia lutea) } \\
\hline Amazona aestiva (CR) & Caatinga, Canudos, Brazil, Jan.-April 2015 & 9 & \multicolumn{3}{|c|}{ fruit pulp (Cactaceae), flowers, bark } \\
\hline Enicognathus ferrugineus (FA) & Urban, Bariloche, Argentina, June-Sept. 2015 & 42 & \multicolumn{3}{|c|}{ fruit pulp (Malus), large seeds (Prunus, Quercus), flower buds, nectar, fungi, grasses } \\
\hline Enicognathus leptorhynchus (CR) & Agro-grazing, Osorno, Chile, Sept. 2015 & 20 & \multicolumn{3}{|c|}{ cereal grain, grasses, flower buds, fungi } \\
\hline Cyanoliseus patagonus $(\mathrm{CR})$ & Steppe, Junín de los Andes, Argentina, Sept. 2015 & 15 & \multicolumn{3}{|l|}{ cereal grain, flower buds, bark } \\
\hline
\end{tabular}

$425{ }^{a}$ CR: communal roost, FA: foraging areas, N: nestling, BC: breeding colony. ${ }^{b}$ note that several faeces showed the simultaneous presence of seeds of several plant

426 species.

427 Table 2. Features of plants and fruits whose seeds were found in parrot faeces, and seed viability according to the tetrazolium test. 


\begin{tabular}{|c|c|c|c|c|c|c|}
\hline Plant species & Growth form & seed size, $\mathrm{mm}(n)$ & Fruit type & Fruit size, $\mathrm{mm}^{\mathrm{b}}$ & No. of seeds ${ }^{b}$ & $\begin{array}{c}\text { tested/viable seeds } \\
\text { (\%viable) }\end{array}$ \\
\hline Rubus sp. & shrub & $2.56 \times 1.51(6)$ & berry & $15.0 \times 15.0$ & 48 & $20 / 0(0.0)$ \\
\hline Maclura tinctoria & tree & $2.15 \times 1.32(1)$ & multiple drupe & $20.0 \times 12.0$ & 50 & $1 / 0(0.0)$ \\
\hline Pilosocereus pachycladus & columnar tree-like cacti & $1.89 \times 1.35(154)^{\mathrm{a}}$ & berry & $50.5 \times 38.1^{1}$ & $3800^{1}$ & $1194 / 490(41.0)$ \\
\hline Tacinga inamoema & opuntiad cacti & $1.98 \times 1.21(6)^{\mathrm{a}}$ & berry & $35.0 \times 30.0^{2}$ & tens $^{3}$ & $4 / 0(0.0)$ \\
\hline Cereus jamacaru & columnar tree-like cacti & $2.62 \times 1.73(20)$ & berry & $82.3 \times 62.6^{4}$ & $1400^{4}$ & $124 / 115(92.7)$ \\
\hline Unindentified Asteraceae & probably herb & $2.09 \times 0.81(4)$ & $?$ & $?$ & $?$ & $4 / 0(0.0)$ \\
\hline Plantago major & herb & $1.77 \times 1.09(2)$ & capsule & $5.0 \times 3.5$ & 10 & $4 / 0(0.0)$ \\
\hline
\end{tabular}

$428 \quad{ }^{a}$ Seeds from faeces of T. acuticaudatus and A. leari.

429 b Approximate mean fruit size and number of seeds per fruit or infrutescence, measured in the field or extracted from the literature $(1=$ Abud et al. $2010,2=$

430 Souza et al. 2007, 3= Menezes et al. 2013, 4= Abud et al. 2013).

431 
433 Figure 1. (A) Partially eaten Pilosocereus pachycladus (Cactaceae) fruit, and (B) detail of its red pulp 434 showing multiple tiny seeds. (C) Adult Lear's Macaw Anodorhynchus leari defecating in flight on a 435 conspecific (probably its mate), which illustrates potential endozoochory and epizoochory. Seeds of 436 Cereus jamacaru (D) and P. pachycladus (E) retrieved from parrot faeces. Photographs by E. Pacifico (A, 437 B), J. Marcos Rosa (C) and C. Bravo (D, E).

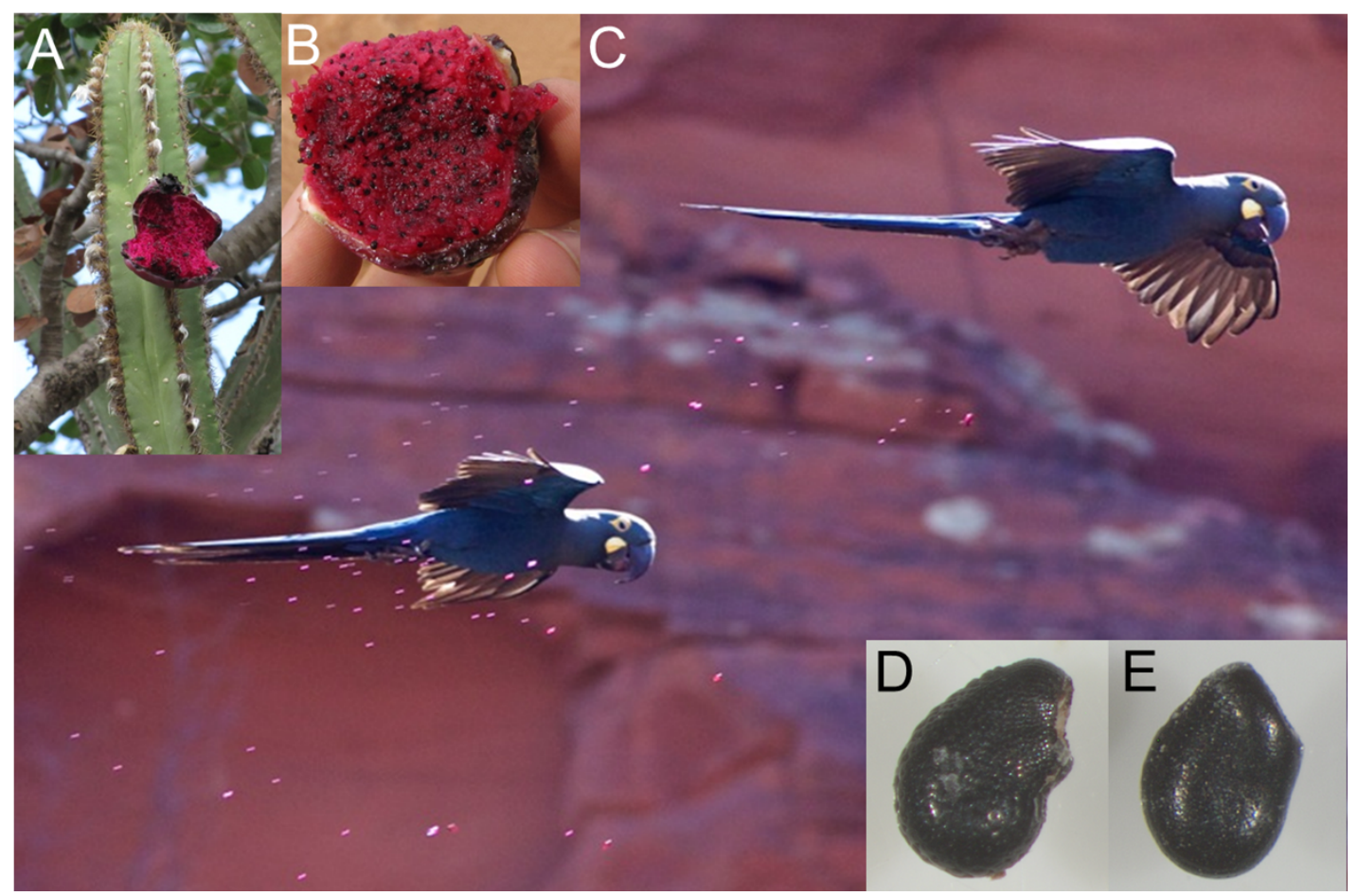


450 Figure 2. Length and width of seeds dispersed by endozoochory (blue circles, this study) and

451 stomatochory by parrots. Data from seeds dispersed by stomatochory (black points) and potential

452 endozoochory (red circles) were extracted from Blanco et al. (2015).

453

454

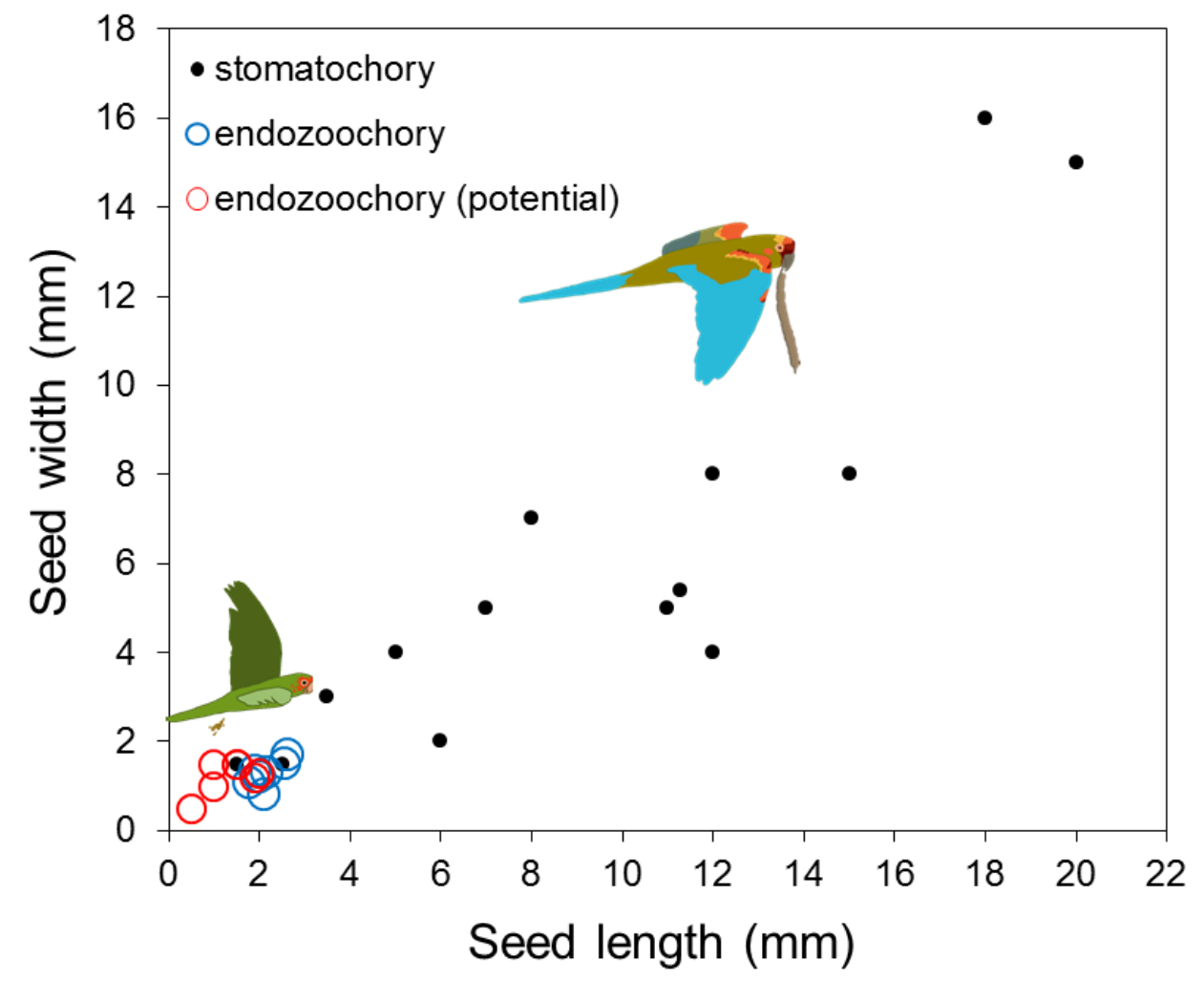

455
456

457

458

459

460

461

462

463 
Figure 3. Size (length and width) of fruits whose seeds were dispersed by endozoochory and stomatochory by parrots. Data were pooled for fruits whose seeds were actually or potentially dispersed internally by parrots; data for fruits dispersed by stomatochory and potential endozoochory was extracted

471 from Blanco et al. (2015). The boxes depict the interquartile ranges (25th to 75 th percentiles), the

472 horizontal thick lines represent the medians, the black squares show the means, the whiskers extend to 1.5 473 times the interquartile range, and the asterisks denote the extreme cases.

474

475

476

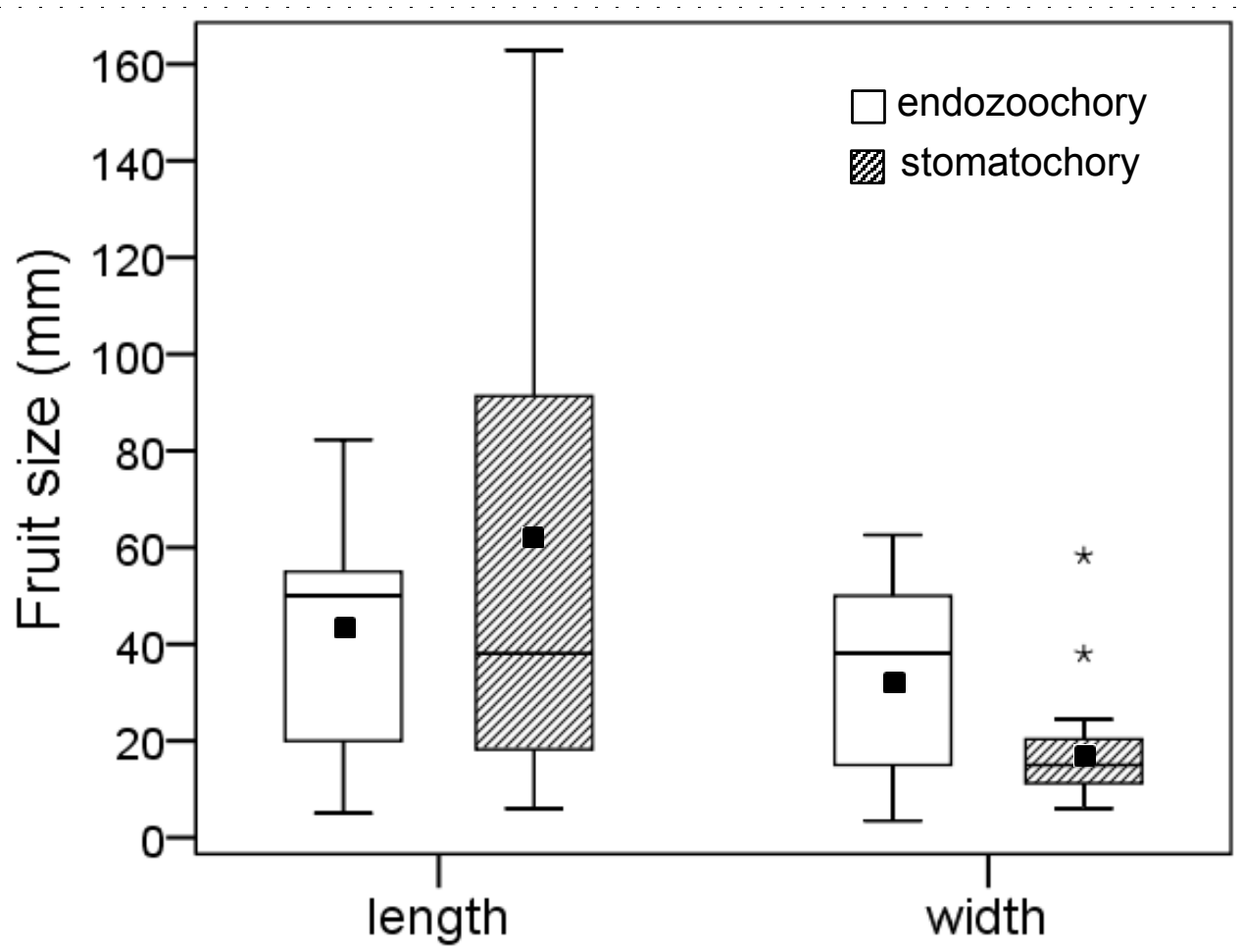

Fruit trait 
